\title{
World Chimpanzee Day and the Ai's Scarf Award
}

\author{
Tetsuro Matsuzawa ${ }^{1,2}$
}

Published online: 21 August 2018

(C) Japan Monkey Centre and Springer Japan KK, part of Springer Nature 2018

\section{World Chimpanzee Day, July 14th}

July the 14th reminds us of Bastille Day. The French Republic has celebrated its national day since 1880 . From this year forward, July 14th is designated as World Chimpanzee Day. Please refer to the detailed explanation given in the following site: https://www.worldchimpanzeeday.org/.

In honor of humans' closest cousin, World Chimpanzee Day is a celebration of chimpanzees and an opportunity to raise awareness about the vital need for worldwide participation in their care, protection, and conservation in the wild and in captivity. Around the globe, so many partners have committed to celebrating World Chimpanzee Day, including IUCN (SSP, Primate Specialist group), to which I belong.

July 14th, 1960 is the day Dr. Jane Goodall first stepped foot in what is now Gombe Stream National Park, to study wild chimpanzees. Dr. Goodall (from now on I call her Jane in this manuscript) called attention to the remarkable chimpanzees and to this day, six decades later, advocates on their behalf. The goals of World Chimpanzee Day are: to celebrate humans' closest cousin in the animal kingdom; raise awareness about threats they face in the wild including habitat loss, disease, and wildlife trafficking; and promote their proper care in captive situations. You can see the various activities on the day around the world. Please go to the homepage to learn about the world-wide efforts.

Tetsuro Matsuzawa

matsuzawa.tetsuro.8w@ kyoto-u.ac.jp

Kyoto University, Kyoto, Japan

2 The Japan Monkey Centre, Inuyama, Japan

\section{Conservation efforts in the wild}

My colleagues and I have been studying wild chimpanzees at Bossou, Guinea, West Africa. The chimpanzees at Bossou use a pair of stones to crack open the hard shells of oil-palm nuts, to eat the edible kernel (Fig. 1). This is a unique tradition of the Bossou community.

However, the number of chimpanzees at Bossou is decreasing (Matsuzawa 2018). We have been doing the Green Corridor Project to plant trees in the savanna to connect Bossou to the neighboring habitats of Mt. Nimba (Matsuzawa et al. 2011).

To celebrate the first World Chimpanzee Day, researchers and local assistants collaborated together with the governmental authority, Institute for Environmental Research of Bossou (IREB), to promote the movement of planting trees for reforestation. The local people were encouraged to go to the savanna with us to work on planting the young trees (Fig. 2). We have been preparing about 10,000 young trees in the tree nursery every year. Planting trees on site might be a good practice for knowing the importance of the forest and for raising awareness about keeping the forests for chimpanzees and other animals.

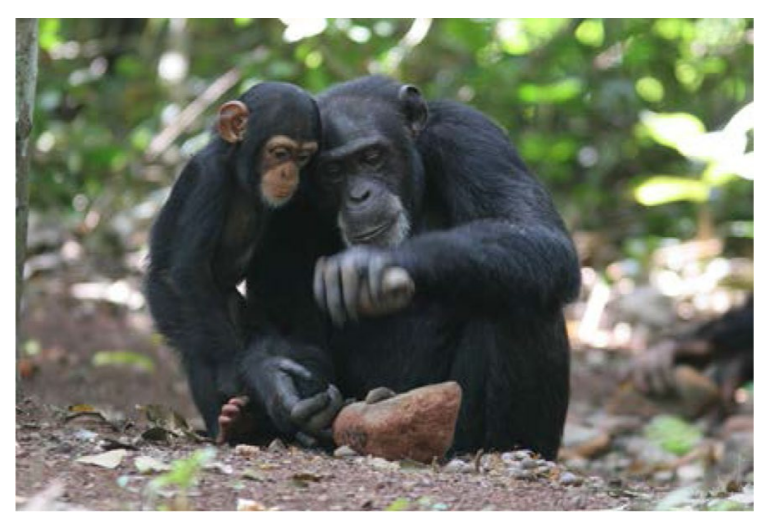

Fig. 1 The chimpanzees of Bossou use a pair of stones to crack open oil-palm nuts (photo provided by the Primate Research Institute of Kyoto University) 


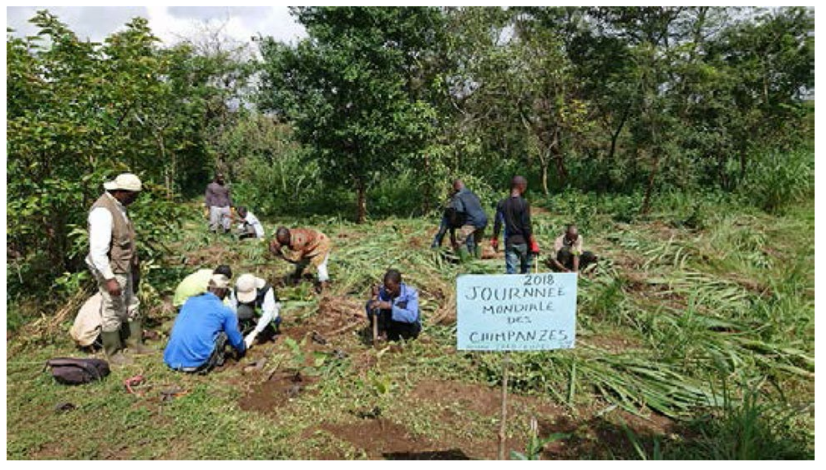

Fig. 2 On the first World Chimpanzee Day, July 14th, 2018, people in Bossou went to the savanna to plant trees in the green corridor to Mt. Nimba (photo provided by the Primate Research Institute of Kyoto University)

\section{A scarf was made from Ai's painting}

Last year was the 40th anniversary of Ai project. On November 10th, 1977, a female chimpanzee named Ai came to the Primate Research Institute (PRI) of Kyoto University when she was 1 year old. She went on to become my research partner since then (Fig. 3).

On an everyday basis, Ai comes to the testing booth to do cognitive tasks such as those involving a computer-controlled monitor. In between the sessions, there is time for playing in a face-to-face situation. Ai sometimes participated in painting. Painting is one of the chimpanzees' favorite activities in general. Please go to the homepage of Chimpanzee Ai and friends to see paintings by PRI chimpanzees. https://urldefense.proofpoint.com/v2/url?u=http-3A_langi nt.pri.kyoto-2Du.ac.jp_ai_en_album_the-5Fdrawings-5Fby5Fchimpanzees.html\&d=DwICJg\&c=vh6FgFnduejNhPP D0fl_yRaSfZy8CWbWnIf4XJhSqx8\&r=i3SHBhGWwB

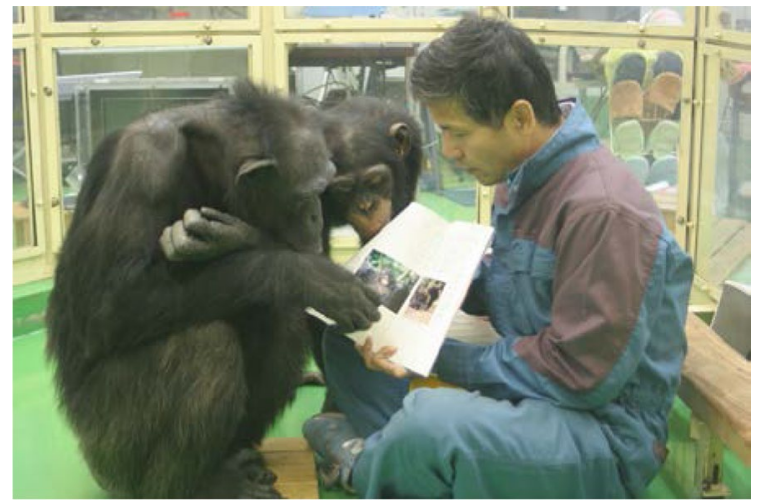

Fig. 3 Chimpanzee Ai gave birth to her son named Ayumu in 2000, when she was 22 years old. We regularly interact with each other face-to-face (photo provided by the Primate Research Institute of Kyoto University)

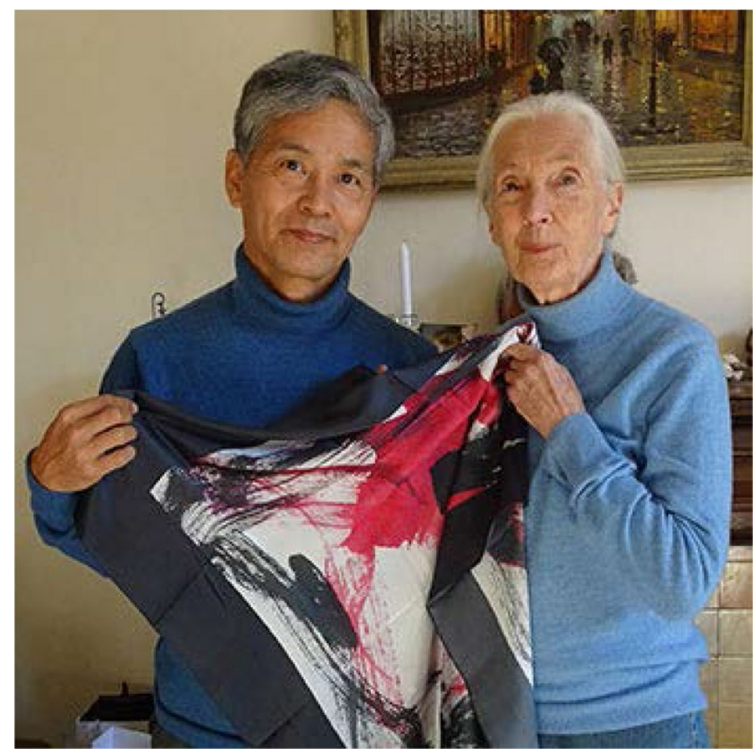

Fig. 4 I gave the silk scarf to Jane Goodall at her home in Bournemouth, UK, in 2017 (photo provided by the Primate Research Institute of Kyoto University)

zPb4cKwtIYxg2_bQeyMAjRhlK887SugvE\&m =C_fqXh9 iZch0S3A5KQhiDtQ51Vw-i_wfiyED_MJgpqg\&s=KtqrH iuvGrE5Qx_GaTWahoTc94MP5B0pWxY1OhU3JvU\&e=.

Prof. Kazuo Oike was the president of Kyoto University and gave much support for our chimpanzee studies. His term in Kyoto University ended and then he moved on to become president of Kyoto University of Arts and Design (KUAD). At that point, he requested from me a painting by Ai. He wanted to put the painting on the wall of his president's room. Dr. Aya Saito, an associate professor of KUAD, studied chimpanzee paintings and helped me to get a painting by Ai. It was Dr. Saito who proposed the idea to use only two colors, red and black, on the white card for autographs. It was chimpanzee $\mathrm{Ai}$ who used the brushes to do the painting.

Prof. Oike really liked the painting by Ai. Then, as president of both KUAD and the Japan Monkey Centre (JMC) since 2014, he got the idea to make a silk scarf from the painting. The scarf was intended to celebrate the 40th anniversary of the Ai project in 2017 (Matsuzawa 2017). He asked a student of KUAD, Ms. Haruka Nomura, majoring in printing arts, to design and make the scarf.

The first sample scarf was made from nylon in August 2016. I brought the first sample to the International Primatological Society (IPS) meeting held in Chicago. I donated the scarf to the silent auction for fund-raising to promote the conservation and welfare of nonhuman primates. This was a test of people's recognition and evaluation of the scarf. As a result, the only scarf in IPS succeeded to get wide and positive attention. Thus, Prof. Oike and I decided to make a real silk scarf. 
Fig. 5 The silk scarf went to three female scholars in 2017. The first one went to Jane Goodall on the February 24th at her home in Bournemouth. The second one went to Sabrina Krief on March 9th in the Muséum National d'Histoire Naturelle in Paris. The third one went to Catherine Hobaiter on March 12th, on the last day of the Scottish Primate Research Group, Burn House meeting in Edzell, Scotland (photo taken by Tetsuro Matsuzawa)
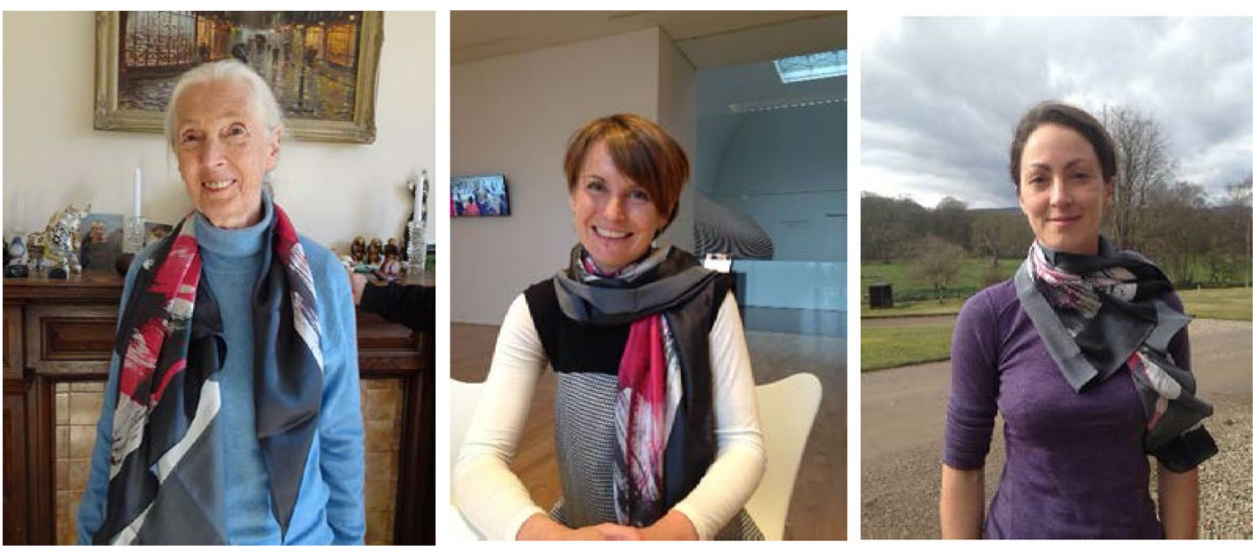

The first scarf in silk reached me in October 2016. There happened to be an opportunity to see the Emperor and Empress who visited Kyoto. They invited three scholars from Kyoto University to the Kyoto Royal Palace; President Juichi Yamagiwa who is also a gorilla researcher, Prof. Shigefumi Mori, majoring in mathematics and the recipient of the Fields Medal, and me. For such occasions, I used to bring my book for a souvenir. However, I decided to bring the silk scarf this time. Thus, the first silk scarf of Ai's painting went to the Empress Michiko on the October 24th, 2016. By the way, whenever I met her, she always asked me two questions. The first is "How is chimpanzee Ai?". She loves to know the story of chimpanzees. The second is "How is Jane?". Jane and the Empress have known each other for a long time. For me, the two ladies look alike and share the same kind of spirit. Jane was born on the April 3rd and the Empress Michiko was born on the October 20th in the same year, 1934.

When I was invited to a symposium on Number Concept held in UK in February 2017, I brought the silk scarf with me. On the way back I visited Jane, who happened to be at home in Bournemouth. I gave the second silk scarf to Jane on the February 24th 2017 (Fig. 4). This is a symbol of appreciation for her lifelong commitment to helping chimpanzees and other animals (Matsuzawa 2017).

\section{Ai's Scarf Award}

In 2017, I used the silk scarf as a very special gift to important persons for me and chimpanzees. I gave the silk scarf to the Crown Princess Masako and then to the Princess Kiko Akishino. The two ladies of the royal family have been always interested in the study of chimpanzees.

I also gave the silk scarf to two more female scholars in 2017. One is Sabrina Krief, who has been studying wild chimpanzees in Kibale forest in Uganda. She is a veterinarian and has reported the bioactive properties of plant species ingested by chimpanzees (Pan troglodytes schweinfurthii) in the wild (Krief et al. 2004, 2005, 2006). Another is Catherine Hobaiter, who has been studying wild chimpanzees in Budongo forest in Uganda. She is one of the pioneers in the study of gestural communication in wild chimpanzees (Hobaiter and Byrne 2011, 2014, 2017). The scarf symbolizes my appreciation of their efforts and those of other female scholars who study wild chimpanzees (see Fig. 5).

Thinking of World Chimpanzee Day, I got the idea of using the silk scarf. Until now, the scarf has not been for sale, but only used as a special gift. Therefore, only a limited number of persons have the scarf; three ladies of the royal family and three female scholars, namely, Jane, Sabrina, and Catherine. Ai's scarf can be a good gift to celebrate World Chimpanzee Day, in which the chimpanzees give back a little something to the dedicated persons.

On July 14th, 2018, the first World Chimpanzee Day, the Japan Monkey Centre declared the founding of Ai's Scarf Award https://urldefense.proofpoint.com/v2/url?u=http3A_langint.pri.kyoto-2Du.ac.jp_ai_en_news_wcd_2018. html\&d=DwICJg\&c=vh6FgFnduejNhPPD0f1_yRaSf Zy8CWbWnIf4XJhSqx8\&r=i3SHBhGWwBzPb4cKwtIY xg2_bQeyMAjRhlK887SugvE\&m=C_fqXh9iZch0S3A5K QhiDtQ51Vw-i_wfiyED_MJgpqg\&s=2GPUKQR7SN TgISCSTKkatuKWh3u9s_CTukfOf3HeYqI\&e=.

Ai's Scarf Award celebrates female scholars who dedicate their lives to promoting the research, conservation, and welfare of chimpanzees and other nonhuman primates. The scarf was created for the 40th anniversary of the Ai project, and is based on a painting by the chimpanzee Ai. The recipient(s) of the 2018 award will be selected by the award committee, established in the Japan Monkey Centre. The award committee 2018 consists of 
three members: Jane Goodall, Juichi Yamagiwa, and Tetsuro Matsuzawa.

Acknowledgements I am grateful to Prof. Kazuo Oike of KUAD and JMC. He gave me opportunities at three stages: Ai's painting, the silk scarf, and Ai's Scarf Award. Financial support for preparing the manuscript came from MEXT-JSPS Grants \#16H06283; the Japan Society for the Promotion of Science (JSPS) Core-to-Core Program CCSN, and the Leading Graduate Program of Primatology and Wildlife Science (U04) to the author. I also thank Dr. James Anderson for editing the English text.

\section{References}

Hobaiter C, Byrne RW (2011) The gestural repertoire of wild chimpanzees. Anim Cogn 14:745-767

Hobaiter C, Byrne RW (2014) The meanings of chimpanzee gestures. Curr Biol 24:1596-1600
Hobaiter C, Byrne RW (2017) What is a gesture? A meaning-based approach to defining gestural repertoires.. Neurosci Biobehav Rev 82:3-12

Krief S, Martin M, Grellier P, Kasenene J, Sévenet T (2004) Novel antimalarial compounds isolated in a survey of self-medicative behavior of wild chimpanzees in Uganda. Antimicrob Agents Chemother 48:3196-3199

Krief S, Hladik CM, Haxaire C (2005) Ethnomedicinal and bioactive properties of plants ingested by wild chimpanzees in Uganda. $\mathrm{J}$ Ethnopharmacol 101:1-3

Krief S, Huffman M, Sévenet T, Hladik CM, Grellier P, Loiseau P, Wrangham R (2006) Bioactive properties of plant species ingested by chimpanzees (Pan troglodytes schweinfurthii) in the Kibale National Park, Uganda. Am J Primatol 68:51-71

Matsuzawa T (2017) The 40th anniversary of the Ai Project: the commemorative gift is a silk scarf painted by Ai the chimpanzee. Primates 58:261-265

Matsuzawa T (2018) Chimpanzee Velu: the wild chimpanzee who passed away at the estimated age of 58. Primates 59:107-111

Matsuzawa T, Humle T, Sugiyama (2011) The chimpanzees of Bossou and Nimba. Springer, Japan 